\title{
Optimal Asset Allocation for a Mean-Variance-CVaR Insurer under Regulatory Constraints
}

\author{
Yu Shi, Xia Zhao, Xin Yan \\ School of Statistics and Information, Shanghai University of International Business and Economics, Shanghai, China \\ Email:xzhao@suibe.edu.cn
}

How to cite this paper: Shi, Y., Zhao, X. and Yan, X. (2019) Optimal Asset Allocation for a Mean-Variance-CVaR Insurer under Regulatory Constraints. American Journal of Industrial and Business Management, 9, 1568-1580.

https://doi.org/10.4236/ajibm.2019.97103

Received: June 6, 2019

Accepted: July 21, 2019

Published: July 24, 2019

Copyright $\odot 2019$ by author(s) and Scientific Research Publishing Inc. This work is licensed under the Creative Commons Attribution International License (CC BY 4.0).

http://creativecommons.org/licenses/by/4.0/

\begin{abstract}
In this paper, we introduce the mean-variance-CVaR criteria into the study of asset allocation for insurers. Considering that the financial market consists of one risk-free asset and multiple risky assets with regulatory constraints, an optimization problem is established for an insurer with underwriting business. Based on practical financial and insurance data, an empirical study is carried out. The results show that the mean-variance-CVaR model is able to provide more potential investment strategies for an insurer. The regulatory policy released by China Insurance Regulatory Commission plays a key role in controlling investment risk for Chinese insurers.
\end{abstract}

\section{Keywords}

Mean-Variance-CVaR Criteria, Optimal Asset Allocation, Insurance, Regulatory Constraints

\section{Introduction}

There has been much attention to the optimal asset allocation problem for insurers recently in the field of risk management and insurance. Early studies about the asset allocation problem for insurers can be seen in Kahane and Nye (1975) [1], Krous (1970) [2], Lambert and Hofflander (1966) [3]. Briys (1985) [4] studies the investment behavior of insurers by maximizing the expected utility based on deterministic underwriting framework. Later, there have been some extended works focusing on the asset allocation problem for insurers based on different optimization objectives (see, e.g., Rong et al. (2001) [5], Rong and Li (2004) [6], Chen et al. (2006) [7], Zhao et al. (2011) [8], Zhao et al. (2018) [9]).

In the above literature, an insurer intends to either maximize the expected 
utility of return or minimize the risk of portfolios. Specifically, for the latter, variance, Value-at-Risk (VaR) or VaR-based risk measure are generally used to characterize risk. As we know, variance, which is generally cared about by traditional fund managers, only focuses on characterizing the fluctuation around the expected return, but ignores the risk in worst-case scenarios. While considering the risk of extreme loss, VaR and Conditional Value-at-Risk (CVaR), etc. are widely used, see, Guo and Li (2009) [10], Xu et al. (2016) [11], Banihashemi (2017) [12], Yu et al. (2011) [13] and the references therein. In particular, CVaR has attracted more attention since it has good theoretical properties, which is consistent with financial practice, see Artzner et al. (1999) [14].

Since different risk measures describe different risk characteristics, it is noteworthy to incorporate two risk measures in an optimization objective. Roman et al. (2007) [15] employ variance and CVaR in the optimal investment problem to get a balanced policy for addressing the requirements of both traditional fund managers and regulators. They find that the mean-variance (MV) model pioneered by Markowitz (1952) [16] and the mean-CVaR model might lead to very different conclusion. The portfolio derived from MV model may have an excessively large $\mathrm{CVaR}$ while that from mean-CVaR model may have an unacceptable variance. However, the proposed mean-variance-CVaR model can generate a series of portfolios which are generally disregarded by $\mathrm{MV}$ and mean-CVaR model. The mean-variance-CVaR model is used for optimizing investment strategy of China sovereign wealth funds by $\mathrm{Yu}$ and Ma (2014) [17]. Using a linear weighted sum method, Younes et al. (2014) [18] devote to simplify the optimization of mean-variance-CVaR model. Chen (2016) [19] analyzes the optimal bond portfolio for commercial bank based on mean-variance-CVaR criterion. And Gao et al. (2016) [20] expand the above static mean-variance-CVaR model to dynamic portfolio selection and derive the analytical forms of the portfolio policy for mean-variance-CVaR optimization models.

So far, few papers have incorporated mean-variance-CVaR criterion into the study of asset allocation strategies for insurance companies. Meanwhile, when Chinese insurers invest in the risk market, they have to consider the constraints on the proportion of investment channels imposed by China Insurance Regulatory Commission (CIRC). Therefore, the main contribution of this paper is that new optimization criterion and regulatory constraints are incorporated into the study of optimal asset allocation problem in insurance risk management. We construct an optimization model based on mean-variance-CVaR criteria for an insurer under the regulatory policies imposed by CIRC. The insurer can invest in a financial market with one risk-free asset and multiple risky assets and underwriting business is also involved. Based on the historical data of the insurance industry and financial market from 2013 to 2017, an empirical study is carried out and the results are analyzed.

The rest of this paper is constructed as follows. In Section 2, we introduce the related risk measures, the return of an insurer and the optimization model with 
regulatory constraints. Section 3 presents the data selection, regulatory policies from CIRC and conducts the empirical study. Section 4 concludes the paper.

\section{Models}

\subsection{Risk Measures}

Suppose that $\boldsymbol{r}=\left(r_{1}, r_{2}, \cdots, r_{n}\right)^{\prime}$ represents return vector, in which $n$ is the number of assets and the corresponding weight vector is denoted by $\boldsymbol{x}=\left(x_{1}, x_{2}, \cdots, x_{n}\right)^{\prime}$, so the total return is $Y=\boldsymbol{r}^{\prime} \boldsymbol{x}$. Variance measures the fluctuation of a random variable around its expected value. Since $Y=\boldsymbol{r}^{\prime} \boldsymbol{x}$, variance of $Y$ can be expressed as,

$$
\mathcal{V}(Y)=\mathcal{V}\left(\boldsymbol{r}^{\prime} \boldsymbol{x}\right)=\sum_{i=1}^{n} \sum_{j=1}^{n} x_{i} x_{j} \sigma_{i j}=\boldsymbol{x}^{\prime} \Sigma \boldsymbol{x},
$$

where $\Sigma=\left(\sigma_{i j}\right)_{n \times n}$ is the covariance matrix of $\boldsymbol{r}$ and $\sigma_{i j}$ is the covariance of $r_{i}$ and $r_{j}$.

Given a certain level of confidence $1-\alpha, \mathrm{VaR}$ measures the greatest potential loss for a portfolio over specific holding period. If the cumulative distribution function for return $Y$ is $F$, VaR can be defined as,

$$
\operatorname{VaR}_{1-\alpha}=-F^{-1}(\alpha) \text {. }
$$

Since VaR does not satisfy the subadditivity (see, Artzner (1999) [14]), a coherent risk measure $\mathrm{CVaR}$ is proposed and defined as follows,

$$
C V a R_{1-\alpha}=E\left[-Y \mid-Y \geq V a R_{1-\alpha}\right] .
$$

Considering the discrete case, Rockafeller and Uryasev (2000, 2002) [20] [21] propose a linear programming model for calculating $\mathrm{CVaR}$, which has been widely used. Suppose that there are $T$ scenarios, every scenario $i(i=1,2, \cdots, T)$ is observed with probabilities $p_{i}$ and every asset $r_{j}(j=1,2, \cdots, n)$ consists of Tobservations $r_{j i}$. Then, CVaR can be formulated as,

$$
C V a R_{1-\alpha}=\min _{\boldsymbol{x}, \xi} \xi+\frac{1}{1-\alpha} \sum_{i=1}^{T} p_{i}\left[-\sum_{j=1}^{n} x_{j} r_{j i}-\xi\right]^{+}
$$

where $\xi$ is $\operatorname{VaR}_{1-\alpha}$.

\subsection{Return of an Insurer}

We assume that an insurer is allowed to invest in $n$ kinds of assets, which consist of one risk-free asset and $n-1$ risky assets. Taking account of underwriting business, the return of the insurer can be expressed as,

$$
r_{p}=r_{b}+g\left(1-\sum_{k=1}^{n-1} x_{i}\right) r_{f}+g \sum_{k=1}^{n-1} x_{k} r_{k}, k=1,2, \cdots, n-1,
$$

where $r_{b}$ is the underwriting return of the insurer; $g$ is the utilization rate of investment capital; $r_{f}$ and $1-\sum_{i=1}^{n-1} x_{k}$ are the return and investment weight of risk-free asset respectively.

Letting $\boldsymbol{w}=\left(w_{0}, w_{1}, \cdots, w_{n-1}\right)^{\prime}=\left(1, g x_{1}, g x_{2}, \cdots, g x_{n-1}\right)^{\prime}$ and 
$\boldsymbol{R}=\left(R_{0}, R_{1}, \cdots, R_{n-1}\right)^{\prime}=\left(r_{b}+g r_{f}, r_{1}-r_{f}, \cdots, r_{n-1}-r_{f}\right)^{\prime}$, Equation (5) can be rewritten as,

$$
r_{p}=\boldsymbol{R}^{\prime} \boldsymbol{w}
$$

\subsection{Mean-Variance-CVaR Model}

Given that the confidence level is $1-\alpha$ and the target return $d$, the optimization problem is established in $T$ scenarios. Based on the idea in Rockafeller and Uryasev (2000) [22], we let every scenario have the same probability, that is $p_{i}=\frac{1}{T}$. And then motivated by Roman et al. (2007) [15], the mean-variance-CVaR model with regulatory constraints is constructed as follows,

$$
\begin{gathered}
\min \mathcal{V}\left(\boldsymbol{R}^{\prime} \boldsymbol{w}\right), \\
\text { s.t. } \operatorname{CVaR}\left(r_{p}\right) \leq c, \\
E\left[\boldsymbol{R}^{\prime} \boldsymbol{w}\right]=d, \\
0 \leq \sum_{k=1}^{n-1} w_{k} \leq g, \\
\operatorname{cons}\left(w_{k}\right), k=1,2, \cdots, n-1,
\end{gathered}
$$

where $\operatorname{cons}(\cdot)$ denotes the relevant regulatory constraints on investment, $d$ is the target return and $c$ is a given $\mathrm{CVaR}$ limit. In addition, since $\sum_{k=1}^{n-1} x_{k}$ is the investment proportion without considering risk-free asset and short selling is not allowed in real Chinese stock, fund and bond market, $0 \leq \sum_{k=1}^{n-1} x_{k} \leq 1$ should be satisfied. Multiplied by $g$ on both sides, we get $0 \leq g \sum_{k=1}^{n-1} x_{k} \leq g$, which can be rewritten as Equation (10) due to the fact that $w_{k}=g x_{k}, k=1,2, \cdots, n-1$.

Remark 1 Different from Roman et al. (2007) [15], here the regulatory constraints are incorporated into the model and risk-free asset is considered in the optimal portfolio.

According to Roman et al. (2007) [15], to ensure the model has efficient solutions, the value of $d$ and $c$ should be chosen appropriately. Specifically, the value of $d$ should lie in the interval $\left[d_{\min }, d_{\max }\right]$. We defined $d_{\text {min }}=\max \left\{d_{\text {min var }}, d_{\operatorname{minCVaR}}\right\}$, where $d_{\text {minvar }}$ and $d_{\operatorname{minCVaR}}$ are the expected returns of the minimum-variance-portfolio and minimum-CVaR-portfolio respectively. And we define $d_{\max }$ as the maximum possible expected return, which is the optimal value of the objective function in the following problem,

$$
\begin{gathered}
\max E\left(\boldsymbol{R}^{\prime} \boldsymbol{w}\right), \\
\text { s.t. } 0 \leq \sum_{k=1}^{n-1} w_{k} \leq g .
\end{gathered}
$$

Furthermore, for a specific $d^{*} \in\left[d_{\min }, d_{\max }\right]$, the level $c$ of $C V a R_{\alpha}$ must lie in the interval $\left[c_{d^{*}, \min }, c_{d^{*}, \max }\right]$, where $c_{d^{*} \text {,min }}$ is the minimum value of $C V a R_{1-\alpha}$ 
for the expected return $d^{*}$ and $c_{d^{*} \text {, } \max }$ is the $C V a R_{1-\alpha}$ of the portfolio generated by MV model with $d^{*}$ (more details, see Roman et al. [15]).

\section{Empirical Study}

\subsection{Data Selection}

According to the actual investment situation of Chinese insurance companies, we consider six kinds of risky assets which consist of government bond (Bond), financial bond (F_bond), corporate bond (C_bond), fund, stock and overseas investment (Overseas) and one risk-free asset (bank deposit).

\subsubsection{Rate of Underwriting Profit}

We collect insurance industry data from China Insurance Regulatory Commission and the statistical data of the national insurance industry in China Insurance Yearbook 2013 to 2017. We are able to get Chinese insurance industry data of premium income, total profit and investment profit (unit: hundred million RMB), which can be denoted as $I, R_{t}$ and $R_{i}$ respectively. Then underwriting profit $R_{u}$ can be calculated by $R_{u}=R_{t}-R_{i}$, and hence the rate of underwriting profit is $r_{b}=\left(R_{t}-R_{i}\right) / I=R_{u} / I$. Related data is shown in Table 1 .

\subsubsection{Utilization Rate of Capital}

According to CIRC's annual statistics report, we organize and calculate the utilization rate of capital in Chinese insurance industry, as shown in Table 2.

Table 1. Data for Chinese insurance industry's underwriting business.

\begin{tabular}{cccc}
\hline Year & $\begin{array}{c}\text { Underwriting } \\
\text { Profit }\left(R_{u}\right)\end{array}$ & Premium Income $(I)$ & $\begin{array}{c}\text { Rate of Underwriting } \\
\text { Profit }\left(r_{b}\right)\end{array}$ \\
\hline 2013 & -2666.90 & 17,222 & $-15.49 \%$ \\
2014 & -3312.20 & 20,235 & $-16.37 \%$ \\
2015 & -4980.00 & 24,283 & $-20.51 \%$ \\
2016 & -5091.88 & 30,959 & $-16.64 \%$ \\
2017 & -5784.91 & 36,581 & $-15.81 \%$ \\
mean & -4367.20 & 25,856 & $-16.89 \%$ \\
\hline
\end{tabular}

Table 2. The utilization rate of capital in Chinese insurance industry.

\begin{tabular}{cc}
\hline Year & The utilization rate of capital $(\mathrm{g})$ \\
\hline 2013 & $92.74 \%$ \\
2014 & $91.85 \%$ \\
2015 & $90.45 \%$ \\
2016 & $88.58 \%$ \\
2017 & $89.07 \%$ \\
mean & $90.54 \%$ \\
\hline
\end{tabular}




\subsubsection{Return of Assets}

We collect data in Chinese financial market. Here three-year bank deposit interest rate $2.75 \%$ is regarded as a return of risk-free asset $\left(r_{f}\right)$, which can be found from the website of the People's Bank of China.

The data of government bond $\left(r_{1}\right)$, financial bond $\left(r_{2}\right)$ and corporate bond $\left(r_{3}\right)$ are collected from Bond Index, Financial Bond Index and Corporate Bond Index in the website of China Securities Index co.Ltd respectively. And for data of fund $\left(r_{4}\right)$, stock $\left(r_{5}\right)$ and overseas investment $\left(r_{6}\right)$, we choose SSE Fund Index, the SSE Composite Index and Hang Seng Composite index respectively (main channel for overseas investment is HongKong securities market because of the policy constraints). Such data is obtained from the website of Shanghai Stock Exchange and HongKong Stock Exchange. We get the daily data of all these indexes from January 1, 2013 to December 31, 2017, and calculate daily logarithm rate of returns. Then the daily logarithm rate of returns of all indexes is transformed to the quarterly rate of returns for each risk asset, which is shown in Table 3.

\subsection{Regulatory Policies}

In terms of the latest regulatory policy ${ }^{1}$ released by the CIRC and in order to

Table 3. The quarterly rate of returns for risky assets.

\begin{tabular}{ccccccc}
\hline Time & Bond $\left(r_{1}\right)$ & $\begin{array}{c}\text { F_bond } \\
\left(r_{2}\right)\end{array}$ & $\begin{array}{c}\text { C_bond } \\
\left(r_{3}\right)\end{array}$ & Fund $\left(r_{4}\right)$ & Stock $\left(r_{5}\right)$ & $\begin{array}{c}\text { Overseas } \\
\left(r_{6}\right)\end{array}$ \\
\hline 2013.1 & 0.0106 & 0.0167 & 0.0238 & -0.0031 & -0.0193 & -0.0474 \\
2013.2 & 0.0099 & 0.0076 & 0.0147 & -0.0692 & -0.1133 & -0.0776 \\
2013.3 & -0.0231 & -0.0136 & -0.0033 & 0.1015 & 0.0971 & 0.1208 \\
2013.4 & -0.0263 & -0.0267 & -0.0178 & -0.0304 & -0.0582 & 0.0177 \\
2014.1 & 0.0246 & 0.0242 & 0.0296 & -0.0491 & -0.0294 & -0.0430 \\
2014.2 & 0.0334 & 0.0356 & 0.0376 & 0.0170 & 0.0015 & 0.0318 \\
2014.3 & 0.0126 & 0.0226 & 0.0252 & 0.1055 & 0.1501 & -0.0073 \\
2014.4 & 0.0348 & 0.0307 & 0.0190 & 0.2846 & 0.3418 & 0.0285 \\
2015.1 & 0.0090 & 0.0004 & 0.0150 & 0.1048 & 0.1288 & 0.0540 \\
2015.2 & 0.0189 & 0.0212 & 0.0290 & 0.0779 & 0.0611 & 0.0372 \\
2015.3 & 0.0220 & 0.0230 & 0.0298 & -0.2097 & -0.2543 & -0.1613 \\
2015.4 & 0.0269 & 0.0287 & 0.0296 & 0.0889 & 0.0468 & -0.0515 \\
2016.1 & 0.0198 & 0.0065 & 0.0171 & -0.0432 & -0.0911 & -0.0410 \\
2016.2 & -0.0015 & 0.0082 & 0.0052 & -0.0020 & -0.0257 & 0.0065 \\
2016.3 & 0.0220 & 0.0167 & 0.0231 & 0.0071 & 0.0387 & 0.1150 \\
2016.4 & -0.0198 & -0.0241 & -0.0196 & 0.0123 & 0.0286 & -0.0600 \\
2017.1 & -0.0034 & -0.0038 & 0.0028 & 0.0176 & 0.0421 & 0.1081 \\
2017.2 & -0.0110 & 0.0053 & 0.0068 & 0.0165 & -0.0229 & 0.0587 \\
2017.3 & 0.0010 & 0.0059 & 0.0129 & 0.0357 & 0.0542 & 0.1122 \\
2017.4 & -0.0055 & -0.0143 & -0.0050 & 0.0101 & 0.0212 & 0.0071 \\
\hline & & & & & & \\
\hline
\end{tabular}

${ }^{1}$ In February 19, 2014, CIRC released policy "Notice on Strengthening and Improving the Regulation of Utilization Ratio of Insurance Capital" to regulate the investment business of Chinese insurers. 
facilitate the calculation, we streamline and summarize the limits of investment ratio for insurers as shown in Table 4.

Since $w_{k}=g x_{k}, k=1, \cdots, 7$, considering the above limits combined with the assumption that short selling is not allowed, Equation (11) can be elaborated as,

$$
\begin{aligned}
0 & \leq w_{1}, w_{2} \leq g, \\
0 & \leq w_{3} \leq 0.5 * g, \\
0 & \leq w_{4} \leq 0.2 * g, \\
0 & \leq w_{5} \leq 0.2 * g, \\
0 & \leq w_{4}+w_{5} \leq 0.3 * g, \\
0 & \leq w_{6} \leq 0.15 * g, \\
g-\sum_{k=1}^{n-1} w_{k} & \geq 0.05 * g, k=1, \cdots, 7 .
\end{aligned}
$$

\subsection{Optimal Asset Allocation under Mean-Variance-CVaR Criteria}

\subsubsection{Descriptive Statistical Analysis}

First of all, we conduct a descriptive statistical analysis of the collected quarterly data of assets and obtain (Table 5). We can conclude that corporate bond has the lowest fluctuation and a relatively high mean value; government bond and financial bond have low fluctuation while low mean value; fund, stock and oversea investment have high return while high risk.

Table 4. Investment constraints from CIRC.

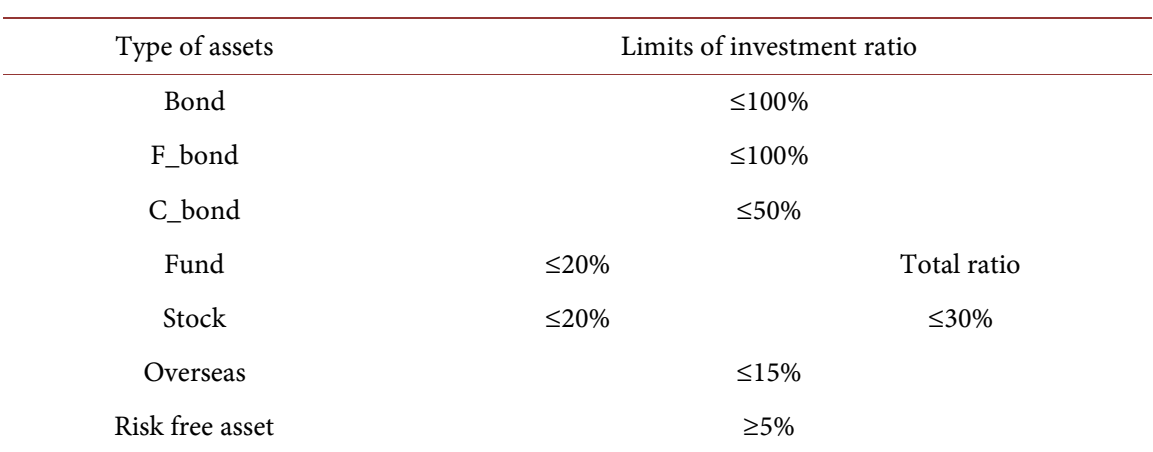

Table 5. Descriptive statistics of quarterly data.

\begin{tabular}{ccccc}
\hline & Mean & Std & Max & Min \\
\hline Deposit $\left(r_{f}\right)$ & 0.0069 & - & - & - \\
$E\left(r_{f}\right)=$ Bond $\left(r_{1}\right)$ & 0.0077 & 0.0184 & 0.0348 & -0.0263 \\
F_bond $\left(r_{2}\right)$ & 0.0085 & 0.0180 & 0.0356 & -0.0267 \\
C_bond $\left(r_{3}\right)$ & 0.0138 & 0.0161 & 0.0376 & -0.0196 \\
Fund $\left(r_{4}\right)$ & 0.0236 & 0.0953 & 0.2846 & -0.2097 \\
Stock $\left(r_{5}\right)$ & 0.0199 & 0.1175 & 0.3418 & -0.2543 \\
Overseas $\left(r_{6}\right)$ & 0.0104 & 0.0740 & 0.1208 & -0.1613
\end{tabular}




\subsubsection{Results for Mean-Variance-CVaR Model}

For mean-variance-CVaR model we consider five levels of expected return, which divide the interval $\left[d_{\min }, d_{\max }\right]$ into 4 equal parts: $d_{1}=d_{\min }=-0.1421$, $d_{2}=-0.1351, d_{3}=-0.1281, d_{4}=-0.1211, d_{5}=d_{\max }=-0.1143$. For each level of expected return $d^{*} \in\left\{d_{1}, d_{2}, d_{3}, d_{4}, d_{5}\right\}$, we determine $c_{d^{*} \text {,min }}$ and $c_{d^{*}, \max }$ (details can be seen in Section 2.3). In addition, the interval $\left[c_{d^{*}, \min }, c_{d^{*}, \max }\right]$ for CVaR is equally divided into 4 equal parts, so five CVaR levels $c^{*} \in\left[c_{d^{*}, \min }, c_{d^{*}, \max }\right]$. We solve the mean-variance-CVaR model with policy constraints for every combination of $d^{*}$ and $c^{*}$. The results are shown in Table 6 and drawn in Figure 1.

With the increasing of the target return, the proportion of bank deposit declines remarkably and the proportion of corporate bond, fund, stock and overseas investment climb up steadily. Corporate bond is the first increasing asset in a portfolio to meet the requirement of higher target return, and reaches the ceiling quickly. Afterwards, in order to further increase the expected return of the portfolio, the proportion of financial bond, fund, overseas investment and stock increase gradually and reach their ceilings finally. It is obvious that the regulatory constraints are active to prevent an insurer investing intensively in single high-return risky asset and to guarantee a certain level of retention of bank deposit.

For every specific level of target return, a larger $c^{*}$ means that the model considers more variance-controlling than $\mathrm{CVaR}$-controlling. In particular, when $c=c_{d^{*}, \min }$, the portfolio is just the mean-CVaR portfolio, and when $c=c_{d^{*} \text {, } \max }$, the portfolio is the mean-variance portfolio. We can see that a larger $c^{*}$ leads to a more diversified portfolio, which has a smaller variance but larger CVaR $\left(c^{*}\right)$. These findings are in line with that in Roman et al. (2007) [15]. Under every specific level of target return, corporate bond shares the same increasing trend due to its good property. But fund and overseas investment have different trends when the level of target return changes from low to high. And When it comes to the highest level of target return, the portfolios are similar if the CVaR constraint $c^{*}$ changes, since all proportion of assets are constrained by the regulatory. Furthermore, as $c^{*}$ moves from $c_{\min }$ to $c_{\max }$, if the target return is relatively low $\left(d^{*}=-0.1421\right.$ or $\left.d^{*}=-0.1351\right)$, the proportion of risk-free asset falls, which means that more capital is invested in risky market. However, if the target return is relatively high $\left(d^{*}=-0.1281\right.$ or $\left.d^{*}=-0.1211\right)$, the proportion of risk-free asset increase gradually, which means that the portfolio is more conservative. We analyze the reason of this finding may be that if the target return is low, both mean-variance and mean-CVaR invest a little capital in risky market, and at this time the "diversification effect theory" of mean-variance model is dominant and leads to more investment proportion in risky market; while if the target return is high, both models have to invest a large proportion of capital, and since CVaR just considers the tail-risk instead of the total fluctuation in optimization, mean-CVaR model is less conservative. 
Table 6. The optimal asset allocation under mean-variance-CVaR model with different $d^{*}$ and $c^{*}$.

\begin{tabular}{|c|c|c|c|c|c|}
\hline \multicolumn{6}{|c|}{$d^{*}=-0.1421$} \\
\hline$c^{*}$ & -0.0318 & -0.0315 & -0.0313 & -0.0310 & -0.0307 \\
\hline Deposit & 0.8969 & 0.8778 & 0.8703 & 0.8774 & 0.8672 \\
\hline Bond & 0.0033 & 0.0242 & 0.0342 & 0.0243 & 0.0313 \\
\hline F_bond & 0 & 0 & 0 & 0.0023 & 0.0007 \\
\hline C_bond & 0.0831 & 0.0848 & 0.0863 & 0.0887 & 0.0993 \\
\hline Fund & 0.0070 & 0.0058 & 0.0055 & 0.0053 & 0.0011 \\
\hline Stock & 0 & 0 & 0 & 0.0004 & 0.0001 \\
\hline Overseas & 0.0097 & 0.0073 & 0.0037 & 0.0017 & 0.0004 \\
\hline $\operatorname{var}\left(10^{-4}\right)$ & 0.211 & 0.197 & 0.188 & 0.185 & 0.178 \\
\hline \multicolumn{6}{|l|}{$d^{*}=-0.1351$} \\
\hline$c^{*}$ & -0.0253 & -0.0252 & -0.0251 & -0.0249 & -0.0248 \\
\hline Deposit & 0.6466 & 0.6433 & 0.6398 & 0.6362 & 0.6327 \\
\hline Bond & 0 & 0 & 0.0001 & 0.0002 & 0.0002 \\
\hline F_bonds & 0 & 0.0001 & 0.0001 & 0.0002 & 0.0002 \\
\hline C_bond & 0.3304 & 0.3356 & 0.3415 & 0.3471 & 0.3527 \\
\hline Fund & 0.0229 & 0.0207 & 0.0181 & 0.0157 & 0.0135 \\
\hline Stock & 0 & 0.0001 & 0 & 0.0001 & 0.0002 \\
\hline Overseas & 0 & 0.0002 & 0.0004 & 0.0005 & 0.0006 \\
\hline $\operatorname{var}\left(10^{-4}\right)$ & 0.297 & 0.295 & 0.293 & 0.292 & 0.291 \\
\hline \multicolumn{6}{|c|}{$d^{*}=-0.1281$} \\
\hline$c^{*}$ & -0.0161 & -0.0151 & -0.0141 & -0.0130 & -0.0120 \\
\hline Deposit & 0.2818 & 0.3039 & 0.3716 & 0.4072 & 0.4279 \\
\hline Bond & 0 & 0 & 0 & 0 & 0.0001 \\
\hline F_bonds & 0.0647 & 0.0673 & 0.0140 & 0.0007 & 0.0001 \\
\hline C_bond & 0.5000 & 0.5000 & 0.5000 & 0.5000 & 0.4999 \\
\hline Fund & 0.0376 & 0.0438 & 0.0544 & 0.0620 & 0.0675 \\
\hline Stock & 0 & 0 & 0 & 0 & 0 \\
\hline Overseas & 0.1159 & 0.0849 & 0.0600 & 0.0302 & 0.0045 \\
\hline $\operatorname{var}\left(10^{-4}\right)$ & 1.5 & 1.25 & 1.05 & 0.895 & 0.819 \\
\hline \multicolumn{6}{|l|}{$d^{*}=-0.1211$} \\
\hline$c^{*}$ & 0.0114 & 0.0128 & 0.0141 & 0.0155 & 0.0168 \\
\hline Deposits & 0.0500 & 0.0535 & 0.0562 & 0.1324 & 0.2186 \\
\hline Bond & 0 & 0.0002 & 0 & 0.0001 & 0.0003 \\
\hline F_bond & 0.1642 & 0.1973 & 0.2329 & 0.1772 & 0.1081 \\
\hline C_bond & 0.5000 & 0.5000 & 0.5000 & 0.5000 & 0.5000 \\
\hline
\end{tabular}


Continued

\begin{tabular}{cccccc}
\hline Fund & 0.1358 & 0.1415 & 0.1473 & 0.1598 & 0.1730 \\
Stock & 0 & 0 & 0 & 0 & 0 \\
Overseas & 0.1500 & 0.1075 & 0.0636 & 0.0304 & 0 \\
var $\left(10^{-4}\right)$ & 4.37 & 3.82 & 3.42 & 3.17 & 2.99 \\
\hline$d^{*}=-0.1143$ & & & & & \\
\hline$c^{*}$ & 0.0538 & 0.0540 & 0.0541 & 0.0543 & 0.0544 \\
Deposits & 0.0500 & 0.0500 & 0.0500 & 0.0500 & 0.0500 \\
Bond & 0 & 0 & 0 & 0 & 0 \\
F_bond & 0.0019 & 0.0035 & 0.0047 & 0.0077 & 0.0090 \\
C_bond & 0.5000 & 0.5000 & 0.5000 & 0.5000 & 0.5000 \\
Fund & 0.2000 & 0.2000 & 0.2000 & 0.2000 & 0.2000 \\
Stock & 0.0981 & 0.0986 & 0.0989 & 0.0996 & 0.1000 \\
Overseas & 0.1500 & 0.1479 & 0.1463 & 0.1427 & 0.1410 \\
var $\left(10^{-4}\right)$ & 12 & 12 & 12 & 12 & 12 \\
\hline
\end{tabular}

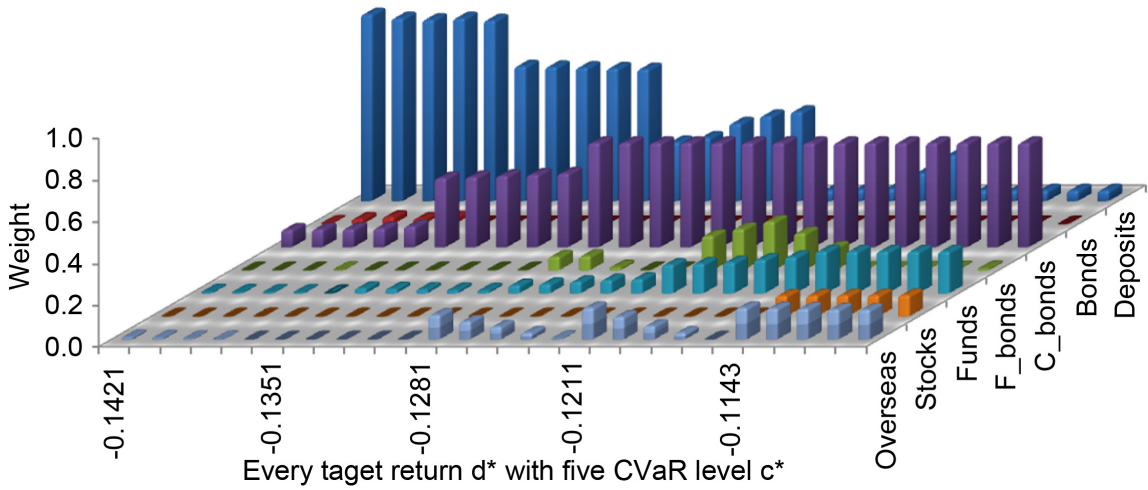

Figure 1. Optimal asset allocation under mean-variance-CVaR model.

In addition, since the mean-variance-CVaR model considers two risk measures, we can find that its optimal portfolios will have neither excessive variance nor excessive CVaR. In other words, it takes into account both the regulators' demand for controlling the left-tail risk and investors' demand for minimizing overall volatility. And the solutions derived from the model are generally discarded by both mean-variance $\left(c=c_{d^{*}, \max }\right)$ and mean-CVaR $\left(c=c_{d^{*}, \min }\right)$ model. It does not mean that mean-variance or mean-CVaR models are dismissed, but on the contrary, the mean-variance-CVaR model reinforces them by providing decision-makers more choices.

\section{Conclusions}

Motivated by Roman et al. (2007) [15], this paper has studied the optimal asset allocation problem under mean-variance-CVaR criteria for an insurer with investment business and underwriting business. Furthermore, the policy 
constraints imposed by CIRC for investment business are considered.

Based on the practical data from Chinese insurance industry and financial market in the period of 2013-2017, an empirical study has been conducted. The empirical results show that there are fewer kinds of asset in the optimal portfolio derived from mean-CVaR than that from mean-variance model and mean-CVaR model does a better job in controlling the tail-risk but ignoring the variance while mean-variance model is opposite. This is consistent with the results in Roman et al. (2007) [15]. Furthermore, we find that, with the target return increasing gradually, as expected, less and less proportion of risk-free asset will be invested. Specifically, more consideration of variance leads to less risk-free asset investing if the target return is relatively low, while leads to more risk-free asset investing if the target return is relatively high. By adjusting the parameters of the constraint for $\mathrm{CVaR}$, mean-variance-CVaR model can take into account the preference between regulators' requirements for short tails and classical fund managers' requirements for small variance, which is more reasonable for insurers under regulatory constraints. In addition, we can find that the constraints imposed by CIRC do work well to limit high-risk investment, especially when insurers intend to go for a high target return. However, current investment channels still can not satisfy the requirement of insurers for making up underwriting losses. Therefore, it's considerable to further expand the investment channels for Chinese insurers to gain more investment profit.

The main contribution of this paper is introducing mean-variance-CVaR model and policy constraints into the empirical study of insurance risk management and some meaningful results are obtained. The study could be extended to a continuous-time setting and the CVaR item in the model could also be incorporated into the objective function to simplify the optimization. We will explore these topics in the following study.

\section{Acknowledgements}

This work was partially supported by National Natural Science Foundation of China (71671104), Project of Humanities Social Sciences of Research of the Ministry of Education, China (16YJA910003, 18YJC630220) and Special Funds of Taishan Scholar Project (tsqn20161041).

\section{Conflicts of Interest}

The authors declare no conflicts of interest regarding the publication of this paper.

\section{References}

[1] Kahane, Y. and Nye, D. (1975) A Portfolio Approach to the Property Liability Insurance Industry. The Journal of Risk and Insurance, 42, 570-598. https://doi.org/10.2307/252154

[2] Krous, C.G. (1970) Portfolio Balancing Corporate Assets and Liabilities with Special 
Application to Insurance Management. The Journal of Financial and Quantitative Analysis, 5, 77-105. https://doi.org/10.2307/2979008

[3] Lambert, E.W. and Hofflander, A.E. (1966) Impact of New Multiple Line Underwriting on Investment Portfolios of Property-Liability Insurers. The Journal of Risk and Insurance, 33, 209-223. https://doi.org/10.2307/251033

[4] Briys, E.P. (1985) Investment Portfolio Behavior of Non-Life Insurers: A Utility Analysis. Insurance: Mathematics and Economics, 4, 93-98. https://doi.org/10.1016/0167-6687(85)90003-4

[5] Rong, X.M., Wu, M.D. and Liu, B.Y. (2001) Research on the Unit Risk-Reture Optimization Model of Insurance Funds Investment. The Journal of Industrial Engineering and Engineering Management, 15, 40-43.

[6] Rong, X.M. and Li, N. (2004) Research on the Optimal Investment of Insurance Funds. The Journal of Quantitative and Technical Economics, 10, 62-67.

[7] Chen, X.H., Han, Z.Z. and Tang, K. (2006) Research on the Optimization Model of Insurance Funds Investment Based on Var and Raroc. The Journal of Quantitative and Technical Economics, 4, 111-117.

[8] Zhao, H., Rong, X.M. and Cao, J.L. (2011) Robust Portfolio Selection Problem for an Insurer with Exponential Utility Preference. WSEAS Transactions on Mathematics, 10, 321-331.

[9] Zhao, X., Ji, H.Y. and Shi, Y. (2018) Optimization Problem of Insurance Investment Based on Spectral Risk Measure and Raroc Criterion. Mathematical Problems in Engineering, 2018, Article ID: 9838437. https://doi.org/10.1155/2018/9838437

[10] Guo, W.J. and Li, X.D. (2009) Optimal Portfolio Selection Bounded by Var for Insurer. Journal of Systems and Management, 18, 118-124.

[11] Xu, Q.F., Zhou, Y.Y., Jiang, C.X., Yu, K.M. and Niu, X.F. (2016) A Large CvaR-Based Portfolio Selection Model with Weight Constraints. Economic Modelling, 59, 436-477. https://doi.org/10.1016/j.econmod.2016.08.014

[12] Banihashemi, S. and Navidi, S. (2017) Portfolio Performance Evaluation in Mean-CvaR Framework: A Comparison with Non-Parametric Methods Value at Risk in Mean-Var Analysis. Operations Research Perspectives, 4, 21-28. https://doi.org/10.1016/j.orp.2017.02.001

[13] Yu, X., Sun, H.G. and Chen, G.H. (2011) The Optimal Portfolio Model Based on Mean-CvaR. Journal of Mathematical Finance, 1, 132-134. https://doi.org/10.4236/jmf.2011.13017

[14] Artzner, P., Delbaen, F., Eber, J.M. and Heath, D. (1999) Coherent Measures of Risk. Mathematical Finance, 9, 203-228. https://doi.org/10.1111/1467-9965.00068

[15] Roman, D., Darby-Dowman, K. and Mitra, G. (2007) Mean-Risk Models Using Two Risk Measures: A Multiobjective Approach. Quantitative Finance, 7, 443-458. https://doi.org/10.1080/14697680701448456

[16] Markowitz, H.M. (1952) Portfolio Selection. The Journal of Finance, 7, 77-91. https://doi.org/10.1111/j.1540-6261.1952.tb01525.x

[17] Elahi, Y. and Abd Aziz, M.I. (2014) China Sovereign Wealth Funds Investment Strategy Based on the Mean-Variance-CvaR. Investment Research, 4, 27-40.

[18] Elahi, Y. and Abd Aziz, M.I. (2014) Mean-Variance-CvaR Model of Multi-Portfolio Optimization via Linear Weighted Sum Method. Mathematical Problems in Engineering, 2014, Article ID: 104064. https://doi.org/10.1155/2014/104064

[19] Chen, H.B. (2016) Research on Bond Portfolio Optimization of Commercial BanksBased on Mean-Variance-CvaR Model. Journal of Finance and Economy, 5, 35-50. 
[20] Gao, J.J., Xiong, Y. and Li, D. (2016) Dynamic Mean-Risk Portfolio Selection with Multiple Risk Measures in Continuous-Time. European Journal of Operational Research, 249, 647-656. https://doi.org/10.1016/j.ejor.2015.09.005

[21] Rockafellar, R.T. and Uryasey, S. (2002) Conditional Value-at-Risk for General Loss Distributions. The Journal of Banking and Finance, 26, 1443-1471. https://doi.org/10.1016/S0378-4266(02)00271-6

[22] Rockafeller, R.T. and Uryasev, S. (2000) Optimization of Conditional Value-at-Risk. Journal of Risk, 2, 21-41. https://doi.org/10.21314/JOR.2000.038 